11-1-2009

\title{
JMASM28: Gibbs Sampling for 2PNO Multi- unidimensional Item Response Theory Models (Fortran)
}

Yanyan Sheng

Southern Illinois University at Carbondale, ysheng@siu.edu

Todd C. Headrick

Southern Illinois University at Carbondale, headrick@siu.edu

Follow this and additional works at: http://digitalcommons.wayne.edu/jmasm

Part of the Applied Statistics Commons, Social and Behavioral Sciences Commons, and the Statistical Theory Commons

\section{Recommended Citation}

Sheng, Yanyan and Headrick, Todd C. (2009) "JMASM28: Gibbs Sampling for 2PNO Multi-unidimensional Item Response Theory Models (Fortran)," Journal of Modern Applied Statistical Methods: Vol. 8 : Iss. 2 , Article 31.

DOI: $10.22237 /$ jmasm/1257035400

Available at: http://digitalcommons.wayne.edu/jmasm/vol8/iss2/31 


\title{
JMASM ALGORITHMS \& CODE JMASM28: Gibbs Sampling for 2PNO Multi-unidimensional Item Response Theory Models (Fortran)
}

\author{
Yanyan Sheng Todd C. Headrick \\ Southern Illinois University Carbondale
}

\begin{abstract}
A Fortran 77 subroutine is provided for implementing the Gibbs sampling procedure to a multiunidimensional IRT model for binary item response data with the choice of uniform and normal prior distributions for item parameters. In addition to posterior estimates of the model parameters and their Monte Carlo standard errors, the algorithm also estimates the correlations between distinct latent traits. The subroutine requires the user to have access to the IMSL library. The source code is available at http://www.siuc.edu/ epse1/sheng/Fortran/MUIRT/GSMU2.FOR. An executable file is also provided for download at http://www.siuc.edu/ epse1/sheng/Fortran/MUIRT/EXAMPLE.zip to demonstrate the implementation of the algorithm on simulated data.
\end{abstract}

Key words: multi-unidimensional IRT model, two-parameter normal ogive model, MCMC, Gibbs sampling, Fortran.

\section{Introduction}

Modeling the interaction of a person's trait and the test at the item level for binary response data, the conventional item response theory (IRT) models rely on a strong assumption of unidimensionality. That is, each test item is designed to measure some facet of a unified latent trait. However, psychological processes have consistently been found to be more complex and an increasing number of educational measurements assess a person on more than one latent trait. In the situations when a test consists of several subtests with each measuring one latent trait, the multi-

Yanyan Sheng is an Associate Professor of Measurement and Statistics. Her areas of research interest are psychometrics, IRT and Bayesian hierarchical models, adaptive testing. Email: ysheng@siu.edu. Todd C. Headrick is Professor of Statistics. Address: Section on Statistics and Measurement, Department of EPSE, 222-J Wham Building, Mail Code 4618, Southern Illinois University-Carbondale, IL, 62901. His areas of research interest are statistical computing, nonparametric statistics, and optimization. Email: headrick@siu.edu. unidimensional IRT models have been found to be more appropriate than the unidimensional models (Sheng \& Wikle, 2007), as they allow inferences to be made about a person for each distinct trait being measured.

For the two-parameter normal ogive (2PNO) multi-unidimensional model, the probability of person $i$ obtaining a correct response for item $j$ in subtest $v$, where $i=1, \ldots, n, \quad j=1, \ldots, k_{v}, \quad v=1, \ldots, m, \quad$ and $K=\sum_{v} k_{v}$, is defined as

$$
\begin{aligned}
P\left(y_{v i j}=1\right) & =\Phi\left(\alpha_{v j} \theta_{v i}-\gamma_{v j}\right) \\
& =\int_{-\infty}^{\alpha_{v j} \theta_{v i}-\gamma_{v j}} \frac{1}{\sqrt{2 \pi}} e^{\frac{-t^{2}}{2}} d t
\end{aligned}
$$

(e.g., Lee, 1995; Sheng \& Wikle, 2007), where $\alpha_{v j}$ and $\theta_{v i}$ are scalar parameters representing the item discrimination and the continuous person trait in the $v$ th latent dimension, and $\gamma_{v j}$ is a scalar parameter indicating the location in that dimension where the item provides maximum information. To estimate both item and person parameters simultaneously, Markov 


\section{SHENG \& HEADRICK}

chain Monte Carlo (MCMC; e.g., Chib \& Greenberg, 1995) techniques are used to summarize the posterior distributions that arise in the context of the Bayesian prior-posterior framework (Carlin \& Louis, 2000; Chib \& Greenberg, 1995; Gelfand \& Smith, 1990; Gelman, Carlin, Stern, \& Rubin, 2003; Tanner \& Wong, 1987). Lee (1995) applied Gibbs sampling (Casella \& George, 1992; Gelfand \& Smith, 1990; Geman \& Geman, 1984), an MCMC algorithm, to the 2PNO multiunidimensional model and illustrated the model parameterization by adopting non-informative priors for item parameters.

Due to the reasons that informative priors are desirable in some applications in the Bayesian framework, and MCMC is computational demanding (see Sheng \& Headrick, 2007, for a description of the problems), this study focuses on using Fortran, the fastest programming language for numerical computing (Brainerd, 2003) to implement the procedure. In particular, the paper provides a Fortran subroutine that obtains the posterior estimates and Monte Carlo standard errors of estimates for the item and person parameters in the 2PNO multi-unidimensional IRT model, as well as the posterior estimates of the correlations between the distinct latent traits. The subroutine allows the user to specify non-informative and informative priors for item parameters.

\section{Methodology}

\section{The Gibbs Sampling Procedure}

To implement Gibbs sampling to the 2PNO multi-unidimensional IRT model defined in (1), a latent continuous random variable $Z$ is introduced so that $Z_{v i j} \sim N\left(\alpha_{v j} \theta_{v i}-\gamma_{v j}, 1\right)$ (Albert, 1992; Lee, 1995; Tanner \& Wong, 1987). Next, denote each person's latent traits for all items as $\boldsymbol{\theta}_{i}=\left(\theta_{1 i}, \ldots, \theta_{m i}\right)^{\prime}$, which is assumed to have a multivariate normal (MVN) distribution, $\boldsymbol{\theta}_{i} \sim N_{m}(\mathbf{0}, \boldsymbol{\Sigma})$, where $\boldsymbol{\Sigma}$ is a correlation matrix, and $\rho_{s t}$ is the correlation between $\theta_{s i}$ and $\theta_{t i}, s \neq t$, on the off diagonals. It may be noted that the unidimensional IRT model is a special case of the multi-unidimensional model where $\rho_{s t}=1$ for all $s, t$. Then, an unconstrained covariance matrix $\Sigma^{*}$ is introduced (Lee, 1995), where $\Sigma^{*}=\left[\sigma_{i j}\right]_{m \times m}$, so that the correlation matrix $\boldsymbol{\Sigma}$ can be easily transformed from $\Sigma^{*}$ using $\rho_{s t}=\frac{\sigma_{s t}}{\sigma_{s} \sigma_{t}}(s \neq t)$. A noninformative prior is assumed for $\Sigma^{*}$ so that $p\left(\Sigma^{*}\right) \propto\left|\Sigma^{*}\right|^{-\frac{m+1}{2}}$. Hence, with prior distributions assumed for $\xi_{v j}$, where $\xi_{v j}=\left(\alpha_{v j}, \gamma_{v j}\right)^{\prime}$, the joint posterior distribution for $\left(\boldsymbol{\theta}, \boldsymbol{\xi}, \mathbf{Z}, \boldsymbol{\Sigma}^{*}\right)$ is

$$
\begin{aligned}
& p\left(\boldsymbol{\theta}, \boldsymbol{\xi}, \mathbf{Z}, \boldsymbol{\Sigma}^{*} \mid \mathbf{y}\right) \propto \\
& \quad f(\mathbf{y} \mid \mathbf{Z}) p(\mathbf{Z} \mid \boldsymbol{\theta}, \boldsymbol{\xi}) p(\boldsymbol{\xi}) p(\boldsymbol{\theta} \mid \boldsymbol{\Sigma}) p\left(\boldsymbol{\Sigma}^{*}\right) .
\end{aligned}
$$

where $f(\mathbf{y} \mid \mathbf{Z})$ is the likelihood function.

With non-informative priors for $\alpha_{v j}$ and $\gamma_{v j}$ so that $\alpha_{v j}>0$ and $p\left(\gamma_{v j}\right) \propto 1$, the full conditional distributions of $Z_{v i j}, \boldsymbol{\theta}_{i}, \boldsymbol{\xi}_{v j}$ and $\boldsymbol{\Sigma}^{*}$ can be derived in closed forms as follows:

$$
Z_{v i j} \cdot \bullet \sim\left\{\begin{array}{c}
N_{(0, \infty)}\left(\alpha_{v j} \theta_{v i}-\gamma_{v j}, 1\right), \text { if } y_{v i j}=1 \\
N_{(-\infty, 0)}\left(\alpha_{v j} \theta_{v i}-\gamma_{v j}, 1\right), \text { if } y_{v i j}=0
\end{array} ;\right.
$$

$$
\boldsymbol{\theta}_{i} \mid \bullet \sim N_{m}\left(\left(\mathbf{A}^{\prime} \mathbf{A}+\boldsymbol{\Sigma}\right)^{-1} \mathbf{A}^{\prime} \mathbf{B},\left(\mathbf{A}^{\prime} \mathbf{A}+\boldsymbol{\Sigma}\right)^{-1}\right),
$$

where $\mathbf{A}_{(K \times m)}=\left(\begin{array}{cccc}\boldsymbol{\alpha}_{1} & \mathbf{0} & \cdots & \mathbf{0} \\ \mathbf{0} & \boldsymbol{\alpha}_{2} & \ldots & \mathbf{0} \\ \vdots & \vdots & \ldots & \vdots \\ \mathbf{0} & \mathbf{0} & \ldots & \boldsymbol{\alpha}_{m}\end{array}\right)$ and

$$
\begin{gathered}
\mathbf{B}_{(K \times 1)}=\left(\begin{array}{c}
\mathbf{Z}_{1 i}+\gamma_{1} \\
\mathbf{Z}_{2 i}+\gamma_{2} \\
\vdots \\
\mathbf{Z}_{m i}+\gamma_{m}
\end{array}\right), \boldsymbol{\alpha}_{v}=\left(\alpha_{v 1}, \ldots, \alpha_{v, k_{v}}\right)^{\prime}, \\
\mathbf{Z}_{v i}=\left(Z_{v i 1}, \ldots, Z_{n i k_{v}}\right)^{\prime}, \gamma_{v}=\left(\gamma_{v 1}, \ldots, \gamma_{v, k_{v}}\right)^{\prime} ; \\
\boldsymbol{\xi}_{v j} \mid \bullet \sim N_{2}\left(\left(\mathbf{x}_{v}{ }^{\prime} \mathbf{x}_{v}\right)^{-1} \mathbf{x}_{v}{ }^{\prime} \mathbf{Z}_{v j},\left(\mathbf{x}_{v}{ }^{\prime} \mathbf{x}_{v}\right)^{-1}\right) I\left(\alpha_{v j}>0\right),
\end{gathered}
$$


where $\mathbf{x}_{v}=\left[\theta_{v},-1\right]$;

$$
\boldsymbol{\Sigma}^{*} \mid \bullet \sim W^{-1}\left(\mathbf{S}^{-1}, n\right)
$$

(an inverse Wishart distribution), where $\mathbf{S}=\sum_{i=1}^{n}\left(c \boldsymbol{\theta}_{i}\right)\left(c \boldsymbol{\theta}_{i}\right)^{\prime}$ and

$c=\left(\begin{array}{cccc}\left(\prod_{j} \alpha_{1 j}\right)^{\frac{1}{k_{1}}} & 0 & \cdots & 0 \\ 0 & \left(\prod_{j} \alpha_{2 j}\right)^{\frac{1}{k_{2}}} & \cdots & 0 \\ \vdots & \vdots & \cdots & \vdots \\ 0 & 0 & \cdots & \left(\prod \alpha_{m j}\right)^{\frac{1}{k_{m}}}\end{array}\right)$

(see Lee, 1995 for a detailed derivation).

Alternatively, conjugate priors can be assumed for $\alpha_{v j}$ and $\gamma_{v j}$ so that $\alpha_{v j} \sim N_{(0, \infty)}\left(\mu_{\alpha_{v}}, \sigma_{\alpha_{v}}^{2}\right), \gamma_{v j} \sim N\left(\mu_{\gamma_{v}}, \sigma_{\gamma_{v}}^{2}\right)$. In this case, the full conditional distribution of $\xi_{v j}$ is derived to be

$$
\begin{array}{r}
\xi_{v j} \mid \bullet \sim N_{2}\left(\left(\mathbf{x}_{v}{ }^{\prime} \mathbf{x}_{v}+\Sigma_{\xi_{v}}^{-1}\right)^{-1}\left(\mathbf{x}_{v}{ }^{\prime} \mathbf{Z}_{v j}+\Sigma_{\xi_{v}}^{-1} \boldsymbol{\mu}_{\xi_{v}}\right),\right. \\
\left.\left(\mathbf{x}^{\prime} \mathbf{x}+\Sigma_{\boldsymbol{\xi}_{v}}^{-1}\right)^{-1}\right) I\left(\alpha_{v j}>0\right)
\end{array}
$$

where

$$
\boldsymbol{\mu}_{\xi_{v}}=\left(\mu_{\alpha_{v}}, \mu_{\gamma_{v}}\right)^{\prime}
$$

and

$$
\boldsymbol{\Sigma}_{\xi_{v}}=\left(\begin{array}{cc}
\sigma_{\alpha_{v}}^{2} & 0 \\
0 & \sigma_{\gamma_{v}}^{2}
\end{array}\right) \text {. }
$$

Hence, with starting values $\boldsymbol{\theta}^{(0)}, \boldsymbol{\xi}^{(0)}$, and $\boldsymbol{\Sigma}^{(0)}$, observations $\left(\mathbf{Z}^{(l)}, \boldsymbol{\theta}^{(l)}, \boldsymbol{\xi}^{(l)}, \boldsymbol{\Sigma}^{(l)}\right)$ can be simulated using the Gibbs sampler by iteratively drawing from their respective full conditional distributions specified in (3), (4), (5), and (6) (or (3), (4), (7), and (6)). In particular, to go from $\left(\mathbf{Z}^{(l-1)}, \boldsymbol{\theta}^{(l-1)}, \xi^{(l-1)}, \boldsymbol{\Sigma}^{(l-1)}\right)$ to $\left(\mathbf{Z}^{(l)}\right.$, $\left.\boldsymbol{\theta}^{(l)}, \boldsymbol{\xi}^{(l)}, \boldsymbol{\Sigma}^{(l)}\right)$, it takes four transition steps:

1. Draw $\mathbf{Z}^{(l)} \sim p\left(\mathbf{Z} \mid \mathbf{y}, \boldsymbol{\theta}^{(l-1)}, \boldsymbol{\xi}^{(l-1)}\right)$;
2. Draw $\boldsymbol{\theta}^{(l)} \sim p\left(\boldsymbol{\theta} \mid \mathbf{Z}^{(l)}, \xi^{(l-1)}, \boldsymbol{\Sigma}^{(l-1)}\right)$;

3. Draw $\xi^{(l)} \sim p\left(\boldsymbol{\xi} \mid \mathbf{Z}^{(l)}, \boldsymbol{\theta}^{(l)}\right)$;

4. Draw $\boldsymbol{\Sigma}^{*(l)} \sim p\left(\boldsymbol{\Sigma}^{*} \mid \boldsymbol{\theta}^{(l)}, \boldsymbol{\xi}^{(l)}\right)$, and transform $\boldsymbol{\Sigma}^{*(l)}$ to $\boldsymbol{\Sigma}^{(l)}$.

This iterative procedure produces a sequence of samples for the model parameters $\left(\boldsymbol{\theta}^{(l)}, \boldsymbol{\xi}^{(l)}\right)$ and the hyperparameter $\boldsymbol{\Sigma}^{(l)}, l=0$, $\ldots, L$. To reduce the effect of the starting values, early iterations in the Markov chain are set as burn-ins to be discarded. Samples from the remaining iterations are then used to summarize the posterior density of item parameters $\xi$, distinct person trait parameters $\boldsymbol{\theta}$, and the correlation matrix $\boldsymbol{\Sigma}$. As with standard Monte Carlo, the posterior means of all the samples collected after burn-in are considered as estimates of the true parameters $\boldsymbol{\xi}, \boldsymbol{\theta}$, and $\boldsymbol{\Sigma}$.

However, the Monte Carlo standard errors cannot be calculated using the sample standard deviations because subsequent samples in each Markov chain are autocorrelated (e.g., Patz \& Junker, 1999). One approach to calculating them is through batching (Ripley, 1987). That is, with a long chain of samples being separated into contiguous batches of equal length, the Monte Carlo standard error for each parameter is then estimated to be the standard deviation of these batch means. The Monte Carlo standard error of estimate is hence a ratio of the Monte Carlo standard error and the square root of the number of batches.

The Fortran Subroutine

The subroutine initially sets the starting values for the model parameters, $\boldsymbol{\theta}, \boldsymbol{\xi}$, and the hyperparameter $\boldsymbol{\Sigma}$, so that $\theta_{v i}^{(0)}=0, \alpha_{v i}^{(0)}=2$, $\gamma_{v i}^{(0)}=-\Phi^{-1}\left(\sum_{i} y_{v i j} / n\right) \sqrt{5}$ (Albert, 1992), and $\boldsymbol{\Sigma}^{(0)}=\mathbf{I}$, with $\mathbf{I}$ being the identity matrix. It then iteratively draws random samples for $\mathbf{Z}, \boldsymbol{\theta}$ and $\boldsymbol{\Sigma}^{*}$ from their respective full conditional distributions specified in (3), (4) and (6). Samples for $\xi_{v j}$ are simulated either from (5), where uniform priors are assumed for $\xi_{v j}$, or from (7), where normal priors are adopted with 


\section{SHENG \& HEADRICK}

$\mu_{\alpha_{v}}=\mu_{\gamma_{v}}=0$ and $\sigma_{\alpha_{v}}^{2}=\sigma_{\gamma_{v}}^{2}=1$. The algorithm continues until all the $L$ samples are simulated. It then discards the early burn-in samples, and computes the posterior estimates and Monte Carlo standard errors of estimates for the model parameters, $\boldsymbol{\theta}$ and $\boldsymbol{\xi}$, as well as the hyperparameter $\boldsymbol{\Sigma}$, using batching.

For example, consider binary responses of 2,000 persons to a total of 16 test items, which are further divided into two subtests so that the first half measures one latent trait and the second half measures another (i.e., $n=$ $2,000, m=2, k_{1}=8, k_{2}=8$, and $K=16$ ). Three dichotomous $(0-1)$ data matrices were simulated from the item parameters shown in the first column of Tables 1 and 2 , so the actual correlation $(\rho)$ between the two distinct latent traits $\left(\theta_{1}, \theta_{2}\right)$ was set to be $0.2,0.5$ and 0.8 , respectively. The Gibbs sampler was implemented to each data set so that 10,000 samples were simulated with the first 5,000 taken to be burn-in. The remaining 5,000 samples were separated into 5 batches, each with 1,000 samples.

With the uniform or the normal prior distributions described previously, two sets of the posterior means for $\alpha_{v}, \gamma_{v}$, and $\rho$ as well as their Monte Carlo standard errors were obtained for each simulated data and are displayed in the rest of the tables. Note that in all the three simulated situations, item parameters were estimated with enough accuracy and the two sets of posterior estimates differed only in the third decimal place, signifying that the results are not sensitive to the choice of prior distributions for $\xi_{v j}$. In addition, the small values of the Monte Carlo standard errors of estimates suggested that the Markov chains with a run length of 10,000 and a burn-in period of 5,000 reached the stationary distribution. Further, note that the procedure recovered the latent structure accurately as well, as the posterior estimates of the correlation between the two distinct latent traits, displayed in the last row of Table 2, was close to the actual correlation in all the three situations. For this example where 2,000-by-16 data matrices were considered, each implementation took less than
25 minutes. The length of the chains may be increased to be as long as 50,000, which takes about 90-120 minutes for each execution.

\section{Conclusion}

This Fortran subroutine allows the user to choose between uniform and normal priors for the item parameters, $\alpha_{v}$ and $\gamma_{v}$. In addition, the user can modify the source code by assigning other values to $\mu_{\alpha}, \sigma_{\alpha}^{2}$, and $\mu_{\gamma}, \sigma_{\gamma}^{2}$ to reflect different prior beliefs on their distributions. Convergence can be assessed by inspecting Monte Carlo standard errors, as well as by comparing the marginal posterior mean and standard deviation of each parameter computed for every 1,000 samples after the burn-ins. For the latter, identical values provide a rough indication of similar marginal posterior densities, which further indicates possible convergence of the Markov chain (Gelfand, Hills, Racine-Poon \& Smith, 1990; Hoijtink \& Molenaar, 1997).

Note that the algorithm adopts a correlation matrix in the prior distribution, $\boldsymbol{\theta}_{i} \sim N_{m}(\mathbf{0}, \boldsymbol{\Sigma})$, to solve the problem of model nonidentifiability (see e.g., Lee, 1995, for a description of the problem). Bafummi, Gelman, Park, and Kaplan (2005) provides an alternative solution to the problem.

\section{References}

Albert, J. H. (1992). Bayesian estimation of normal ogive item response curves using Gibbs sampling. Journal of Educational Statistics, 17, 251-269.

Bafumi, J., Gelman, A., Park, D. K., \& Kaplan, N. (2005). Practical issues in implementing and understanding Bayesian ideal point estimation. Political Analysis, 13, 171187.

Brainerd, W. (2003). The importance of Fortran in the $21^{\text {st }}$ century. Journal of Modern Statistical Methods, 2, 14-15.

Casella, G., \& George, E. I. (1992). Explaining the Gibbs sampler. The American Statistician, 46, 167-174.

Carlin, B. P., \& Louis, T. A. (2000). Bayes and empirical Bayes methods for data analysis $\left(2^{\text {nd }} E d\right.$.). London: Chapman \& Hall. 
Table 1: Posterior Estimates and Monte Carlo Standard Errors of Estimates (MCSEs) for $\alpha_{v}$ with Uniform and Normal Priors

\begin{tabular}{|c|c|c|c|c|c|c|}
\hline \multirow[b]{3}{*}{ Parameters } & \multicolumn{2}{|c|}{$\rho=.2$} & \multicolumn{2}{|c|}{$\rho=.5$} & \multicolumn{2}{|c|}{$\rho=.8$} \\
\hline & Uniform & Normal & Uniform & Normal & Uniform & Normal \\
\hline & $\begin{array}{l}\text { Estimate } \\
\text { (MCSE) }\end{array}$ & $\begin{array}{l}\text { Estimate } \\
\text { (MCSE) }\end{array}$ & $\begin{array}{l}\text { Estimate } \\
\text { (MCSE) }\end{array}$ & $\begin{array}{l}\text { Estimate } \\
\text { (MCSE) }\end{array}$ & $\begin{array}{l}\text { Estimate } \\
\text { (MCSE) }\end{array}$ & $\begin{array}{l}\text { Estimate } \\
\text { (MCSE) }\end{array}$ \\
\hline \multicolumn{7}{|l|}{$\alpha_{1}$} \\
\hline 0.0966 & $\begin{array}{l}0.0838 \\
(.0013)\end{array}$ & $\begin{array}{l}0.0828 \\
(.0011)\end{array}$ & $\begin{array}{l}0.0869 \\
(.0007)\end{array}$ & $\begin{array}{l}0.0846 \\
(.0012)\end{array}$ & $\begin{array}{l}0.0830 \\
(.0013)\end{array}$ & $\begin{array}{l}0.0847 \\
(.0007)\end{array}$ \\
\hline 0.0971 & $\begin{array}{l}0.0675 \\
(.0010)\end{array}$ & $\begin{array}{l}0.0660 \\
(.0013)\end{array}$ & $\begin{array}{l}0.0731 \\
(.0008)\end{array}$ & $\begin{array}{l}0.0740 \\
(.0010)\end{array}$ & $\begin{array}{l}0.0657 \\
(.0014)\end{array}$ & $\begin{array}{l}0.0689 \\
(.0012)\end{array}$ \\
\hline 0.4589 & $\begin{array}{l}0.4698 \\
(.0035)\end{array}$ & $\begin{array}{l}0.4704 \\
(.0026)\end{array}$ & $\begin{array}{l}0.4748 \\
(.0028)\end{array}$ & $\begin{array}{l}0.4707 \\
(.0021)\end{array}$ & $\begin{array}{l}0.4829 \\
(.0021)\end{array}$ & $\begin{array}{l}0.4797 \\
(.0021)\end{array}$ \\
\hline 0.9532 & $\begin{array}{l}0.8556 \\
(.0039)\end{array}$ & $\begin{array}{l}0.8531 \\
(.0069)\end{array}$ & $\begin{array}{l}0.8804 \\
(.0054)\end{array}$ & $\begin{array}{l}0.8753 \\
(.0058)\end{array}$ & $\begin{array}{l}0.8937 \\
(.0063)\end{array}$ & $\begin{array}{l}0.8928 \\
(.0045)\end{array}$ \\
\hline 0.0771 & $\begin{array}{l}0.0510 \\
(.0009)\end{array}$ & $\begin{array}{l}0.0502 \\
(.0005)\end{array}$ & $\begin{array}{l}0.0552 \\
(.0013)\end{array}$ & $\begin{array}{l}0.0550 \\
(.0008)\end{array}$ & $\begin{array}{l}0.0589 \\
(.0007)\end{array}$ & $\begin{array}{l}0.0577 \\
(.0008)\end{array}$ \\
\hline 0.4891 & $\begin{array}{l}0.4900 \\
(.0020)\end{array}$ & $\begin{array}{l}0.4895 \\
(.0024)\end{array}$ & $\begin{array}{l}0.4855 \\
(.0029)\end{array}$ & $\begin{array}{l}0.4864 \\
(.0012)\end{array}$ & $\begin{array}{l}0.4659 \\
(.0017)\end{array}$ & $\begin{array}{l}0.4649 \\
(.0017)\end{array}$ \\
\hline 0.8599 & $\begin{array}{l}1.0401 \\
(.0185)\end{array}$ & $\begin{array}{l}1.0348 \\
(.0114)\end{array}$ & $\begin{array}{l}1.0180 \\
(.0080)\end{array}$ & $\begin{array}{l}1.0120 \\
(.0069)\end{array}$ & $\begin{array}{l}0.9983 \\
(.0057)\end{array}$ & $\begin{array}{l}0.9930 \\
(.0061)\end{array}$ \\
\hline 0.9427 & $\begin{array}{l}0.9381 \\
(.0075) \\
\end{array}$ & $\begin{array}{l}0.9327 \\
(.0024) \\
\end{array}$ & $\begin{array}{l}0.9477 \\
(.0085) \\
\end{array}$ & $\begin{array}{l}0.9408 \\
(.0088) \\
\end{array}$ & $\begin{array}{l}0.9628 \\
(.0033) \\
\end{array}$ & $\begin{array}{l}0.9479 \\
(.0075) \\
\end{array}$ \\
\hline \multicolumn{7}{|l|}{$\alpha_{2}$} \\
\hline 0.2727 & $\begin{array}{l}0.3013 \\
(.0010)\end{array}$ & $\begin{array}{l}0.2973 \\
(.0026)\end{array}$ & $\begin{array}{l}0.2654 \\
(.0006)\end{array}$ & $\begin{array}{l}0.2685 \\
(.0014)\end{array}$ & $\begin{array}{l}0.2348 \\
(.0016)\end{array}$ & $\begin{array}{l}0.2358 \\
(.0013)\end{array}$ \\
\hline 0.6532 & $\begin{array}{r}0.7279 \\
(.0051) \\
\end{array}$ & $\begin{array}{l}0.7251 \\
(.0061) \\
\end{array}$ & $\begin{array}{l}0.6354 \\
(.0028) \\
\end{array}$ & $\begin{array}{l}0.6346 \\
(.0020)\end{array}$ & $\begin{array}{l}0.7188 \\
(.0042)\end{array}$ & $\begin{array}{l}0.7142 \\
(.0028)\end{array}$ \\
\hline 0.1002 & $\begin{array}{l}0.1231 \\
(.0010)\end{array}$ & $\begin{array}{l}0.1226 \\
(.0014)\end{array}$ & $\begin{array}{l}0.1528 \\
(.0008)\end{array}$ & $\begin{array}{l}0.1527 \\
(.0012)\end{array}$ & $\begin{array}{l}0.1088 \\
(.0012)\end{array}$ & $\begin{array}{l}0.1108 \\
(.0018)\end{array}$ \\
\hline 0.2339 & $\begin{array}{l}0.0945 \\
(.0014)\end{array}$ & $\begin{array}{l}0.0965 \\
(.0026)\end{array}$ & $\begin{array}{l}0.1557 \\
(.0021)\end{array}$ & $\begin{array}{l}0.1535 \\
(.0015)\end{array}$ & $\begin{array}{l}0.1683 \\
(.0020)\end{array}$ & $\begin{array}{l}0.1670 \\
(.0013)\end{array}$ \\
\hline 0.9291 & $\begin{array}{l}0.8554 \\
(.0155)\end{array}$ & $\begin{array}{l}0.8552 \\
(.0131)\end{array}$ & $\begin{array}{l}0.8145 \\
(.0042)\end{array}$ & $\begin{array}{l}0.8184 \\
(.0071)\end{array}$ & $\begin{array}{l}0.9208 \\
(.0039)\end{array}$ & $\begin{array}{l}0.9149 \\
(.0061)\end{array}$ \\
\hline 0.8618 & $\begin{array}{l}0.8730 \\
(.0128)\end{array}$ & $\begin{array}{l}0.8575 \\
(.0095)\end{array}$ & $\begin{array}{l}0.9107 \\
(.0060)\end{array}$ & $\begin{array}{l}0.9001 \\
(.0069)\end{array}$ & $\begin{array}{l}0.9067 \\
(.0034)\end{array}$ & $\begin{array}{l}0.9055 \\
(.0050)\end{array}$ \\
\hline 0.0908 & $\begin{array}{l}0.0543 \\
(.0006) \\
\end{array}$ & $\begin{array}{l}0.0518 \\
(.0016) \\
\end{array}$ & $\begin{array}{l}0.0556 \\
(.0005) \\
\end{array}$ & $\begin{array}{l}0.0570 \\
(.0007) \\
\end{array}$ & $\begin{array}{l}0.0463 \\
(.0010) \\
\end{array}$ & $\begin{array}{l}0.0464 \\
(.0007) \\
\end{array}$ \\
\hline 0.2083 & $\begin{array}{l}0.2003 \\
(.0006)\end{array}$ & $\begin{array}{l}0.1967 \\
(.0021)\end{array}$ & $\begin{array}{l}0.2045 \\
(.0016)\end{array}$ & $\begin{array}{l}0.2035 \\
(.0010)\end{array}$ & $\begin{array}{l}0.2339 \\
(.0013)\end{array}$ & $\begin{array}{l}0.2351 \\
(.0007)\end{array}$ \\
\hline
\end{tabular}


Table 2: Posterior Estimates and Monte Carlo Standard Errors of Estimates (MCSEs) for $\gamma_{v}$ and $\rho$ with Uniform and Normal Priors

\begin{tabular}{|c|c|c|c|c|c|c|}
\hline \multirow[b]{3}{*}{ Parameters } & \multicolumn{2}{|c|}{$\rho=.2$} & \multicolumn{2}{|c|}{$\rho=.5$} & \multicolumn{2}{|c|}{$\rho=.8$} \\
\hline & Uniform & Normal & Uniform & Normal & Uniform & Normal \\
\hline & $\begin{array}{l}\text { Estimate } \\
\text { (MCSE) }\end{array}$ & $\begin{array}{l}\text { Estimate } \\
\text { (MCSE) }\end{array}$ & $\begin{array}{l}\text { Estimate } \\
\text { (MCSE) }\end{array}$ & $\begin{array}{l}\text { Estimate } \\
\text { (MCSE) }\end{array}$ & $\begin{array}{l}\text { Estimate } \\
\text { (MCSE) }\end{array}$ & $\begin{array}{l}\text { Estimate } \\
\text { (MCSE) }\end{array}$ \\
\hline \multicolumn{7}{|l|}{$\gamma_{1}$} \\
\hline 0.3629 & $\begin{array}{l}0.3457 \\
(.0007)\end{array}$ & $\begin{array}{l}0.3447 \\
(.0003)\end{array}$ & $\begin{array}{l}0.3467 \\
(.0010)\end{array}$ & $\begin{array}{l}0.3448 \\
(.0005)\end{array}$ & $\begin{array}{l}0.3450 \\
(.0004)\end{array}$ & $\begin{array}{l}0.3452 \\
(.0005)\end{array}$ \\
\hline-0.9010 & $\begin{array}{c}-0.8881 \\
(.0003)\end{array}$ & $\begin{array}{l}-0.8875 \\
(.0002)\end{array}$ & $\begin{array}{l}-0.8891 \\
(.0006)\end{array}$ & $\begin{array}{l}-0.8885 \\
(.0006)\end{array}$ & $\begin{array}{l}-0.8875 \\
(.0005)\end{array}$ & $\begin{array}{r}-0.8865 \\
(.0003)\end{array}$ \\
\hline-0.9339 & $\begin{array}{c}-0.9288 \\
(.0017)\end{array}$ & $\begin{array}{r}-0.9277 \\
(.0017)\end{array}$ & $\begin{array}{c}-0.9288 \\
(.0018)\end{array}$ & $\begin{array}{l}-0.9270 \\
(.0012)\end{array}$ & $\begin{array}{l}-0.9317 \\
(.0015)\end{array}$ & $\begin{array}{c}-0.9310 \\
(.0011)\end{array}$ \\
\hline-0.3978 & $\begin{array}{l}-0.3976 \\
(.0023)\end{array}$ & $\begin{array}{l}-0.3983 \\
(.0017)\end{array}$ & $\begin{array}{r}-0.4035 \\
(.0018)\end{array}$ & $\begin{array}{l}-0.4012 \\
(.0016)\end{array}$ & $\begin{array}{l}-0.4059 \\
(.0020)\end{array}$ & $\begin{array}{c}-0.4062 \\
(.0018)\end{array}$ \\
\hline 0.3987 & $\begin{array}{l}0.4077 \\
(.0003)\end{array}$ & $\begin{array}{l}0.4076 \\
(.0008)\end{array}$ & $\begin{array}{l}0.4085 \\
(.0006)\end{array}$ & $\begin{array}{l}0.4072 \\
(.0006)\end{array}$ & $\begin{array}{l}0.4073 \\
(.0002)\end{array}$ & $\begin{array}{l}0.4066 \\
(.0007)\end{array}$ \\
\hline 0.1654 & $\begin{array}{l}0.1679 \\
(.0003)\end{array}$ & $\begin{array}{l}0.1681 \\
(.0005)\end{array}$ & $\begin{array}{l}0.1675 \\
(.0009)\end{array}$ & $\begin{array}{l}0.1666 \\
(.0007)\end{array}$ & $\begin{array}{l}0.1665 \\
(.0010)\end{array}$ & $\begin{array}{l}0.1669 \\
(.0008)\end{array}$ \\
\hline-0.8108 & $\begin{array}{r}-0.8302 \\
(.0082)\end{array}$ & $\begin{array}{c}-0.8294 \\
(.0062)\end{array}$ & $\begin{array}{l}-0.8232 \\
(.0032)\end{array}$ & $\begin{array}{l}-0.8186 \\
(.0039)\end{array}$ & $\begin{array}{l}-0.8122 \\
(.0030)\end{array}$ & $\begin{array}{l}-0.8091 \\
(.0030)\end{array}$ \\
\hline-0.8012 & $\begin{array}{c}-0.7091 \\
(.0025)\end{array}$ & $\begin{array}{c}-0.7064 \\
(.0019)\end{array}$ & $\begin{array}{c}-0.7145 \\
(.0043)\end{array}$ & $\begin{array}{c}-0.7102 \\
(.0043)\end{array}$ & $\begin{array}{c}-0.7186 \\
(.0012)\end{array}$ & $\begin{array}{c}-0.7140 \\
(.0048)\end{array}$ \\
\hline \multicolumn{7}{|l|}{$\gamma_{2}$} \\
\hline 0.2452 & $\begin{array}{l}0.2902 \\
(.0008)\end{array}$ & $\begin{array}{l}0.2896 \\
(.0007)\end{array}$ & $\begin{array}{l}0.3122 \\
(.0005)\end{array}$ & $\begin{array}{l}0.3109 \\
(.0002)\end{array}$ & $\begin{array}{l}0.3037 \\
(.0006)\end{array}$ & $\begin{array}{l}0.3047 \\
(.0005)\end{array}$ \\
\hline 0.9792 & $\begin{array}{l}1.0954 \\
(.0031)\end{array}$ & $\begin{array}{l}1.0941 \\
(.0032)\end{array}$ & $\begin{array}{l}1.0476 \\
(.0015)\end{array}$ & $\begin{array}{l}1.0461 \\
(.0024)\end{array}$ & $\begin{array}{l}1.1095 \\
(.0021)\end{array}$ & $\begin{array}{l}1.1045 \\
(.0016)\end{array}$ \\
\hline-0.0190 & $\begin{array}{l}-0.0216 \\
(.0006)\end{array}$ & $\begin{array}{l}-0.0212 \\
(.0005)\end{array}$ & $\begin{array}{l}-0.0058 \\
(.0006)\end{array}$ & $\begin{array}{l}-0.0068 \\
(.0002)\end{array}$ & $\begin{array}{l}-0.0200 \\
(.0005)\end{array}$ & $\begin{array}{c}-0.0196 \\
(.0009)\end{array}$ \\
\hline 0.8749 & $\begin{array}{l}0.9549 \\
(.0005)\end{array}$ & $\begin{array}{l}0.9536 \\
(.0006)\end{array}$ & $\begin{array}{l}0.9624 \\
(.0008)\end{array}$ & $\begin{array}{l}0.9616 \\
(.0009)\end{array}$ & $\begin{array}{l}0.9568 \\
(.0014)\end{array}$ & $\begin{array}{l}0.9538 \\
(.0005)\end{array}$ \\
\hline-0.3119 & $\begin{array}{c}-0.2139 \\
(.0026)\end{array}$ & $\begin{array}{l}-0.2143 \\
(.0013)\end{array}$ & $\begin{array}{r}-0.2049 \\
(.0019)\end{array}$ & $\begin{array}{l}-0.2068 \\
(.0011)\end{array}$ & $\begin{array}{l}-0.2250 \\
(.0005)\end{array}$ & $\begin{array}{c}-0.2256 \\
(.0011)\end{array}$ \\
\hline 0.2005 & $\begin{array}{l}0.2902 \\
(.0025)\end{array}$ & $\begin{array}{l}0.2888 \\
(.0024)\end{array}$ & $\begin{array}{l}0.2781 \\
(.0021)\end{array}$ & $\begin{array}{l}0.2735 \\
(.0019)\end{array}$ & $\begin{array}{l}0.2777 \\
(.0012)\end{array}$ & $\begin{array}{l}0.2750 \\
(.0022)\end{array}$ \\
\hline 0.4626 & $\begin{array}{l}0.4658 \\
(.0011)\end{array}$ & $\begin{array}{l}0.4638 \\
(.0004)\end{array}$ & $\begin{array}{l}0.4514 \\
(.0004)\end{array}$ & $\begin{array}{l}0.4501 \\
(.0002)\end{array}$ & $\begin{array}{l}0.4550 \\
(.0005)\end{array}$ & $\begin{array}{l}0.4545 \\
(.0012)\end{array}$ \\
\hline 0.7184 & $\begin{array}{l}0.7528 \\
(.0008)\end{array}$ & $\begin{array}{l}0.7510 \\
(.0007)\end{array}$ & $\begin{array}{l}0.7485 \\
(.0007)\end{array}$ & $\begin{array}{l}0.7462 \\
(.0007)\end{array}$ & $\begin{array}{l}0.7738 \\
(.0003)\end{array}$ & $\begin{array}{l}0.7723 \\
(.0013)\end{array}$ \\
\hline$\rho$ & $\begin{array}{l}0.1850 \\
(.0022)\end{array}$ & $\begin{array}{l}0.1853 \\
(.0018)\end{array}$ & $\begin{array}{l}0.5209 \\
(.0031)\end{array}$ & $\begin{array}{l}0.5213 \\
(.0036)\end{array}$ & $\begin{array}{l}0.7872 \\
(.0037)\end{array}$ & $\begin{array}{l}0.7942 \\
(.0041)\end{array}$ \\
\hline
\end{tabular}




\section{GIBBS SAMPLING FOR 2PNO MULTI-UNIDIMENSIONAL ITEM RESPONSE MODELS}

Chib, S., \& Greenberg, E. (1995). Understanding the Metropolis-Hastings algorithm. The American Statistician, 49, 327335.

Gelfand, A. E., \& Smith, A. F. M. (1990). Sampling-based approaches to calculating marginal densities. Journal of the American Statistical Association, 85, 398-409.

Gelfand, A. E., Hills, S. E., RacinePoon, A., \& Smith, A. F. M. (1990). Illustration of Bayesian inference in normal data models using Gibbs sampling. Journal of the American Statistical Association, 85, 315-331.

Geman, S., \& Geman, D. (1984). Stochastic relaxation, Gibbs distributions, and the Bayesian restoration of images. IEEE Trans. Pattern Analysis and Machine Intelligence, 6, 721-741.

Gelman, A., Carlin, J. B., Stern, H. S., \& Rubin, D. B. (2003). Bayesian data analysis. Boca Raton: Chapman \& Hall/CRC.

Hoijtink, H., \& Molenaar, I. W. (1997). A multidimensional item response model: Constrained latent class analysis using posterior predictive checks. Psychometrika, 62, 171-189.
Lee, H. (1995). Markov chain Monte Carlo methods for estimating multidimensional ability in item response analysis. Ph.D. Dissertation, University of Missouri, Columbia, MO.

Patz, R. J., \& Junker, B. W. (1999). A straightforward approach to Markov chain Monte Carlo methods for item response models. Journal of Educational and Behavioral Statistics, 24, 146-178.

Ripley, B. D. (1987). Stochastic simulation. NY: Wiley.

Sheng, Y., \& Headrick, T. C. (2007). An algorithm for implementing Gibbs sampling for 2PNO IRT models. Journal of Modern Applied Statistical Methods, 6, 341-249.

Sheng, Y., \& Wikle, C. K. (2007). Comparing multi-unidimensional and unidimensional IRT Models. Educational \& Psychological Measurement, 67, 899-919.

Tanner, M. A., \& Wong, W. H. (1987). The calculation of posterior distribution by data augmentation (with discussion). Journal of the American Statistical Association, 82, 528-550.

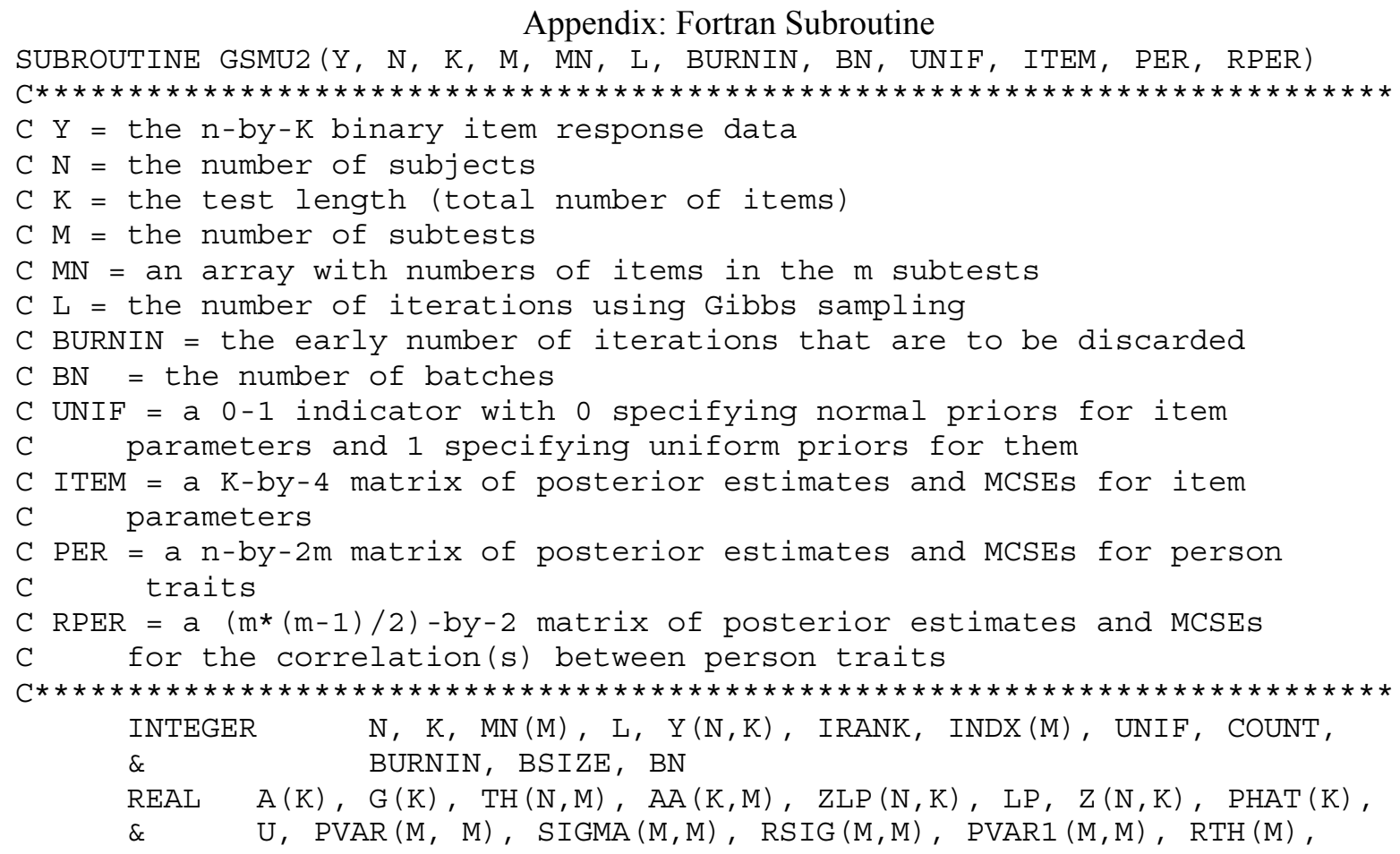


$\& \quad \operatorname{BA}(\mathrm{K}), \operatorname{PMEAN1}(\mathrm{M}), \operatorname{PMEAN}(\mathrm{M}), \mathrm{X}(\mathrm{N}, 2), \mathrm{XX}(2,2), \mathrm{IX}(2,2), \mathrm{RMN}(\mathrm{M})$, $\& \quad \mathrm{ZV}(\mathrm{N}, 1), \mathrm{XZ}(2,1), \operatorname{AMAT}(2,2), \mathrm{BZ}(2,1), \mathrm{AMU}, \mathrm{GMU}, \mathrm{AVAR}, \mathrm{GVAR}$, $\& \quad \operatorname{AgMU}(2,1), \operatorname{AgVAR}(2,2), \operatorname{AgSig}(2,2), \operatorname{BETA}(2), \mathrm{C}(\mathrm{M}, \mathrm{M}), \mathrm{CTH}(\mathrm{M}, \mathrm{N})$, $\& \quad \mathrm{D}(\mathrm{M}, \mathrm{M}), \mathrm{AV}(\mathrm{L}, \mathrm{K}), \mathrm{GV}(\mathrm{L}, \mathrm{K}), \operatorname{RHO}(\mathrm{M}, \mathrm{M}, \mathrm{L}), \operatorname{THV}(\mathrm{N}, \mathrm{M}, \mathrm{L}), \operatorname{ITEM}(\mathrm{K}, 4)$, \& $\quad \operatorname{PER}(\mathrm{N}, 2 * \mathrm{M})$, SUM0, SUM1, SUM2, SUM3, M0, M1, M2, M3, TOT, \& TOT1, TOT2, TOT3, SS, SS1, SS2, SS3, $\operatorname{RPER}(\mathrm{M} *(\mathrm{M}-1) / 2,2)$, $\& \quad$ PRODA, $\operatorname{VAR}(\mathrm{M}, \mathrm{M})$ DOUBLE PRECISION BB, TMP

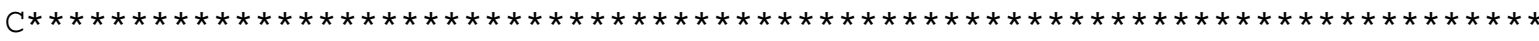
C Connect to external libraries for normal (RNNOR), uniform (RNUN), and C multivariate normal (RNMVN) random number generator, inverse (DNORIN) $C$ and CDF (ANORDF, DNORDF) for the standard normal distribution, and C Cholesky factorization (CHFAC) routines

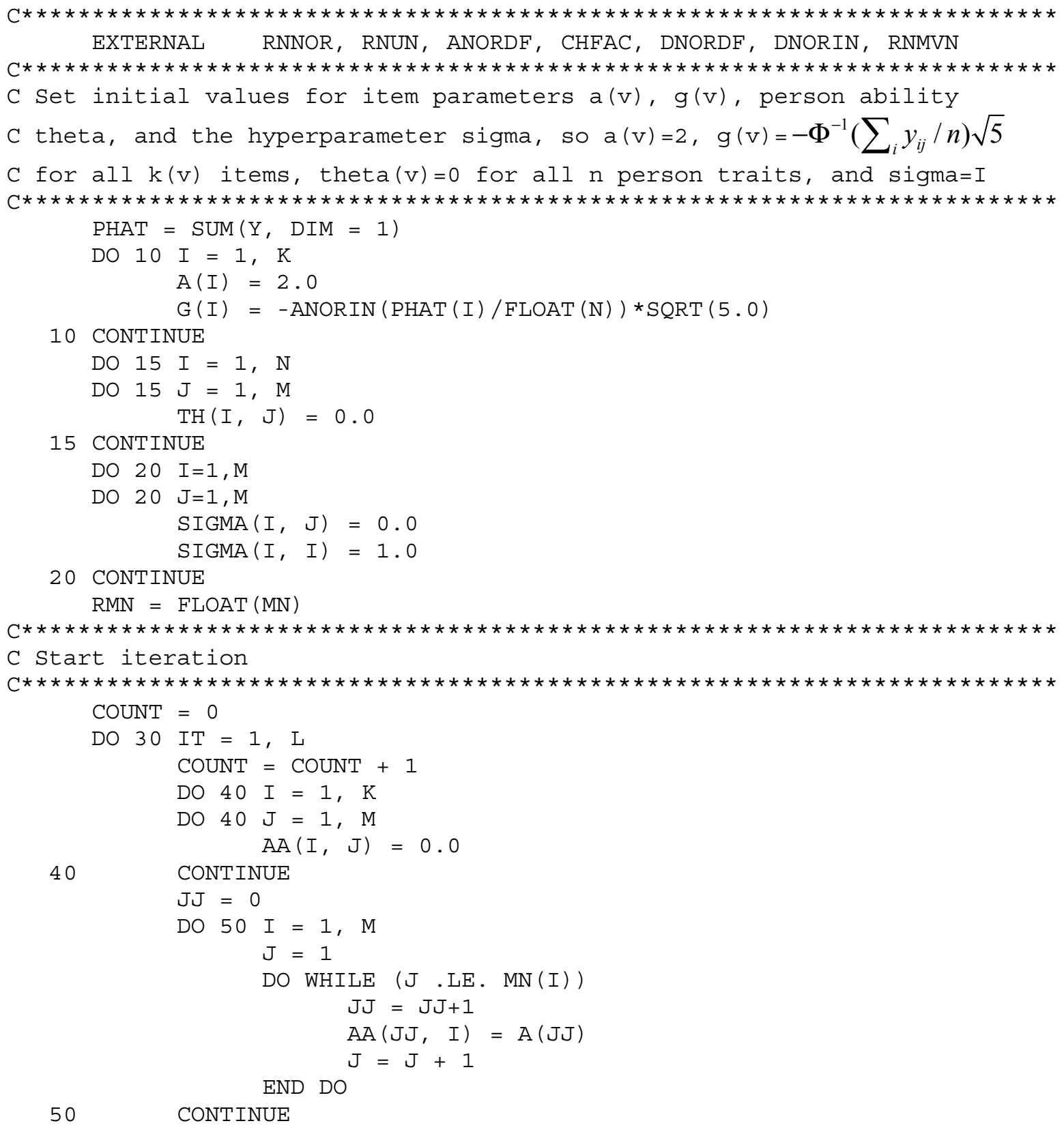




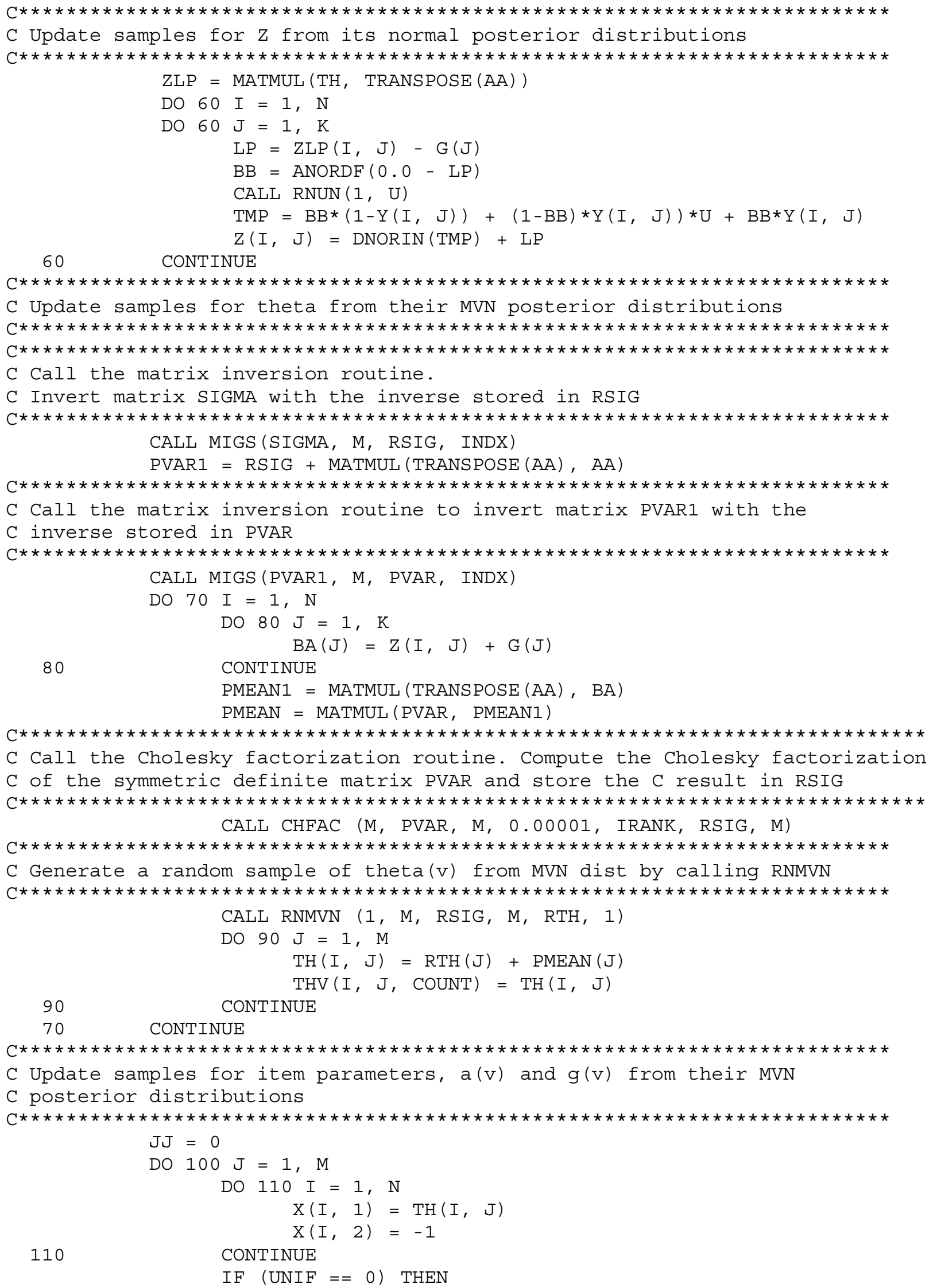




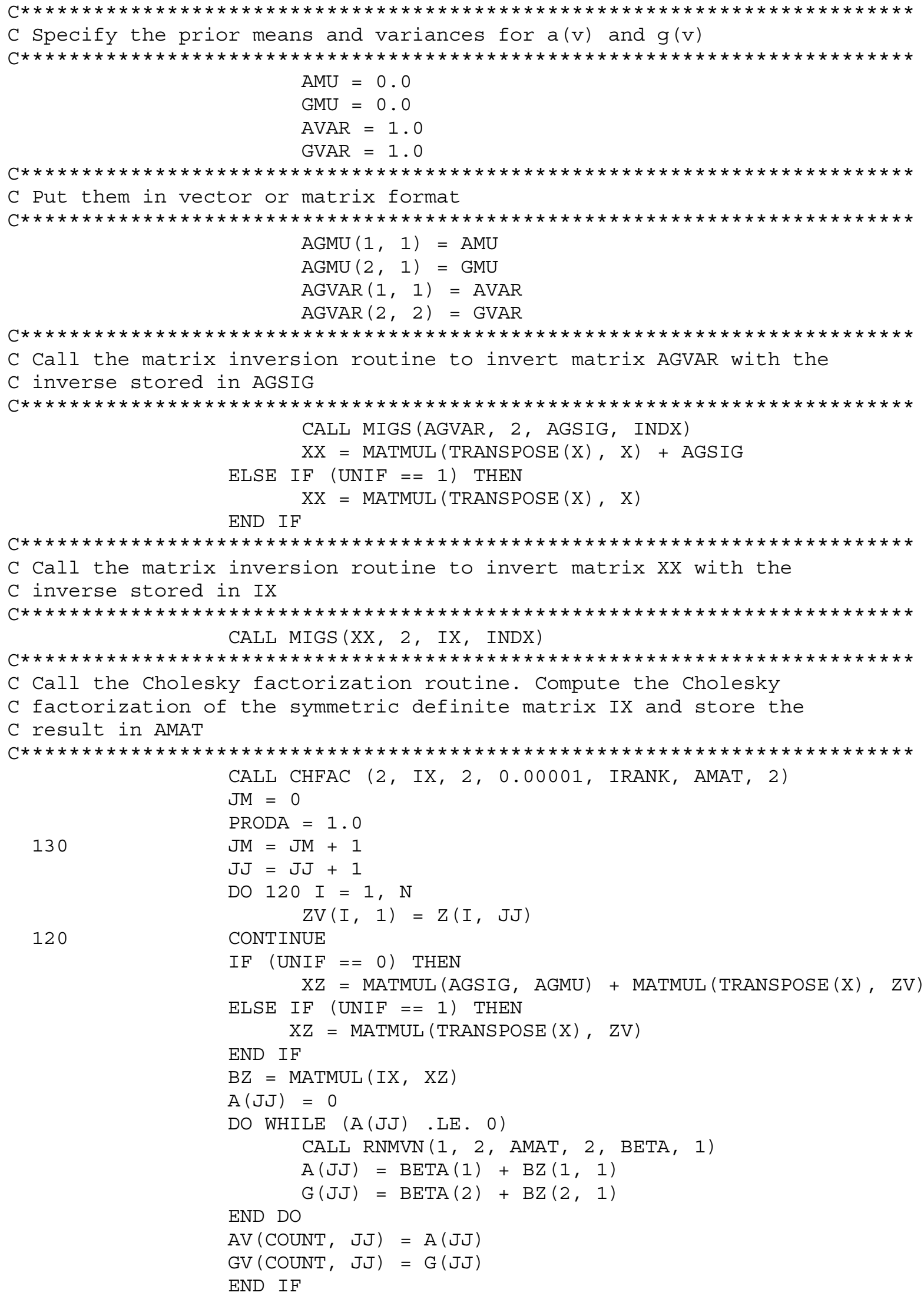




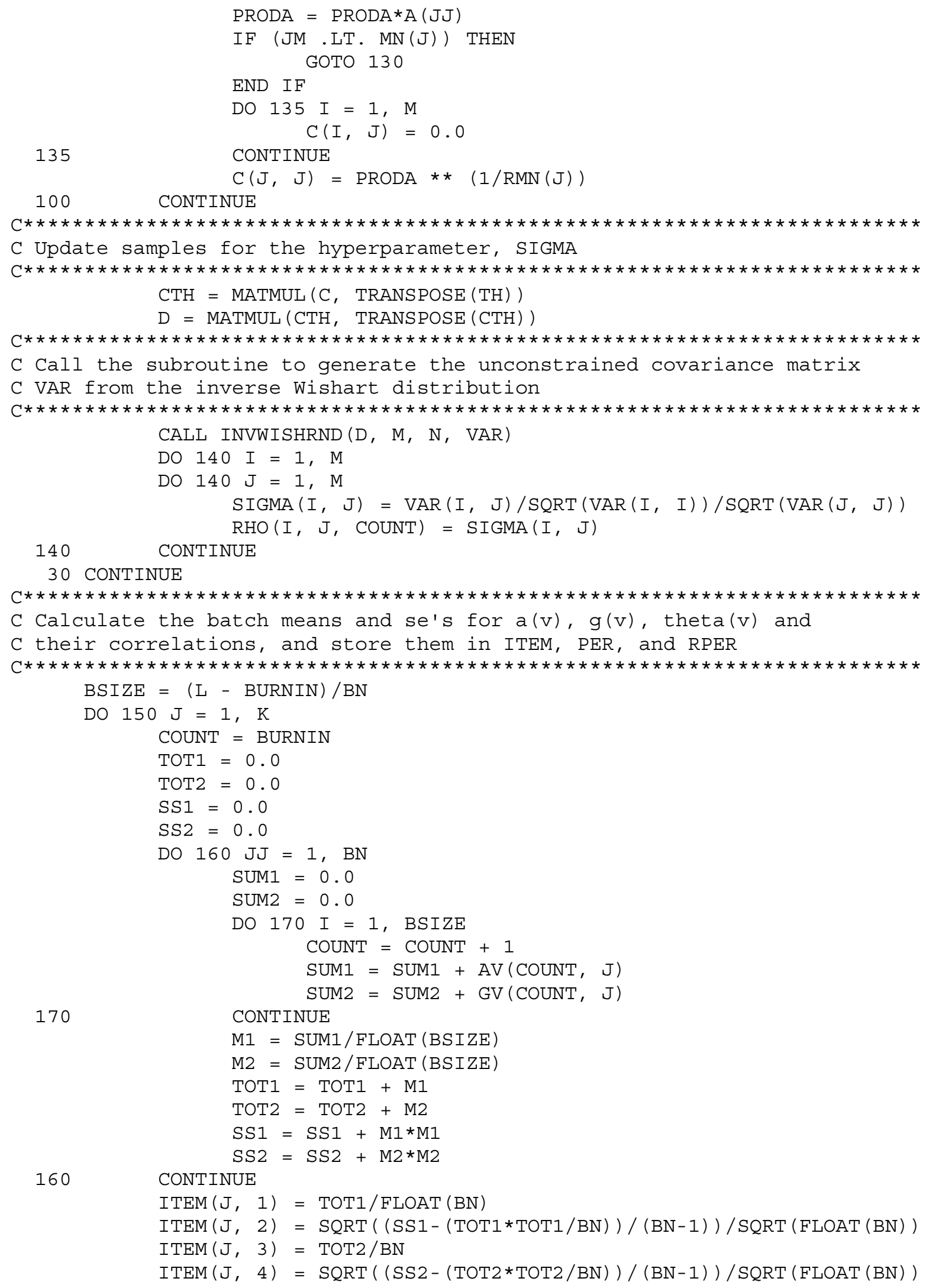




\section{SHENG \& HEADRICK}

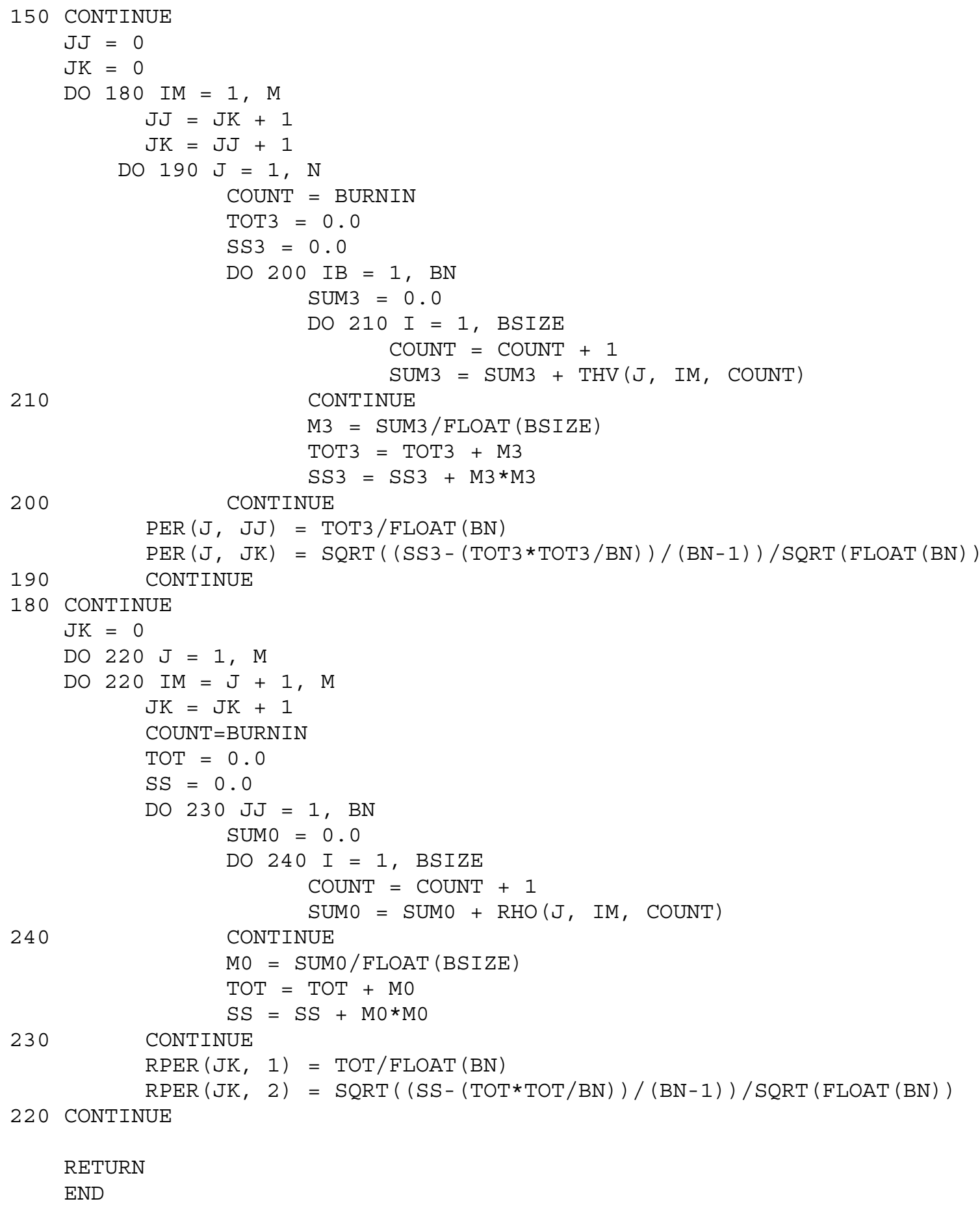




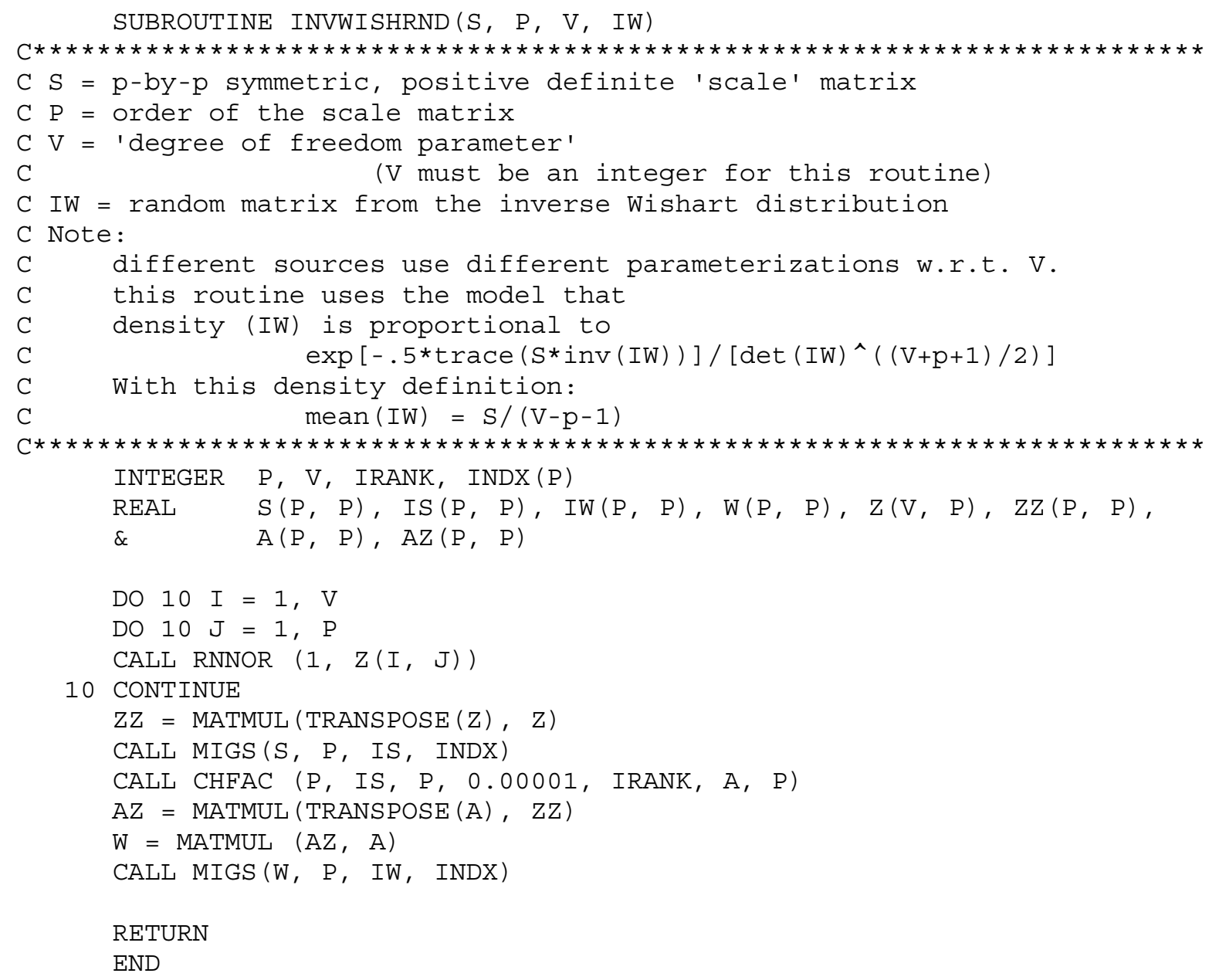

